\title{
Evidências no desenvolvimento da liderança em enfermagem com o uso da pesquisa-ação: revisão integrativa
}

\author{
Bárbara Souza Rocha ${ }^{1}$, Denize Bouttelet Munari ${ }^{2}$, Luana Cássia Miranda Ribeiro ${ }^{3}$, Lara Gomes Rego ${ }^{4}$
}

\footnotetext{
${ }^{1}$ Enfermeira, Doutora em Enfermagem. Professora Adjunta da Faculdade de Enfermagem da Universidade Federal de Goiás. Goiânia, GO, Brasil. E-mail: barbarasrocha@gmail.com.

${ }^{2}$ Enfermeira, Doutora em Enfermagem. Professora Titular Aposentada da Faculdade de Enfermagem da Universidade Federal de Goiás. Goiânia, GO, Brasil. Email: boutteletmunari@gmail.com.

${ }^{3}$ Enfermeira, Doutora em Enfermagem. Professora Adjunta da Faculdade de Enfermagem da Universidade Federal de Goiás. Goiânia, GO, Brasil. E-mail:

luaufg@yahoo.com.br.

${ }^{4}$ Acadêmica do curso de Graduação em Enfermagem da Faculdade de Enfermagem da Universidade Federal de Goiás. Goiânia, GO, Brasil. E-mail: gore21ljo@gmail.com.
}

Recebido: 09/05/2017.

Aceito: 10/08/2017.

Publicado: 28/11/2017.

\section{Como citar esse artigo:}

Rocha BS, Munari DB, Ribeiro LCM, Rego PG. Evidências no desenvolvimento da liderança em enfermagem com o uso da pesquisa-ação: revisão integrativa. Rev. Eletr. Enf. [Internet]. 2017 [acesso em: ____;19:a41. Disponível em: http://dx.doi.org/10.5216/ree.v19.46827.

\section{RESUMO}

Este estudo teve como objetivo identificar as evidências sobre os efeitos do uso da pesquisa-ação no desenvolvimento da liderança em enfermagem. Revisão integrativa da literatura realizada no ano de 2016, orientada pelos descritores "Action Research" and "Nursing", na qual foram incluídos um total de oito artigos. Evidenciou-se que a maioria das pesquisas foram desenvolvidas no contexto hospitalar, compreendendo estudos descritivos de abordagem qualitativa, que apresentaram como objetivo o processo de mudança na prática do enfermeiro. Quanto às evidências no desenvolvimento da liderança em enfermagem, os artigos apontaram para a importância do processo de tomada de decisão compartilhada como sendo a habilidade fundamental para a liderança. A construção conjunta de ferramentas de gestão mostrou-se essencial para alicerçar os processos de mudanças na prática, principalmente, no que se refere para a continuidade e permanência de qualificação dos profissionais para a liderança.

Descritores: Pesquisa em Administração de Enfermagem; Liderança; Pesquisa Qualitativa; Gestão em Saúde; Enfermagem.

\section{INTRODUÇÃO}

O enfermeiro é considerado um profissional estratégico para a gestão em saúde e agente de transformação por sua expressiva atuação na liderança ${ }^{(1)}$, conceituada nesse estudo, como habilidade de influência interpessoal exercida e concretizada quando o líder inspira e é validada por seus pares e forma novas lideranças ${ }^{(2)}$. Por essa razão, é tão importante para esse profissional o investimento no aprimoramento constante de boas práticas de liderança, fundamentadas em inteligência emocional, cultural e política, 
perspicácia financeira, boa capacidade de comunicação, conhecimentos sobre o ambiente e clima organizacional e foco na gestão de pessoas ${ }^{(1-4)}$.

Estudo realizado no Brasil sobre o conhecimento produzido pela enfermagem, especificamente, relativo à área do gerenciamento ${ }^{(5)}$ o que inclui estudos sobre liderança, apontou para a necessidade de se avançar no desenvolvimento de pesquisas com maior aprofundamento teórico e com delineamento metodológico mais robusto de forma a produzir maior impacto na prática.

As investigações que tratam do tema têm apontado que é fundamental para melhorar o desempenho do enfermeiro em liderança, o desenvolvimento do autoconhecimento ${ }^{(1,3,5)}$, de habilidades relacionais com ênfase na comunicação assertiva e o trabalho em equipe ${ }^{(6)}$ e de inovação nos processos de capacitação para ampliar a visibilidade do trabalho desse profissional ${ }^{(4)}$. Essas ações indicam que se espera da liderança em enfermagem uma atuação efetiva e transformadora, o que se alinha aos fundamentos da liderança transformacional, caracterizada pela capacidade do líder em inspirar e formar seguidores, orientá-los para mudanças, com base em compromisso ético e responsável com os resultados ${ }^{(7)}$. Esse estilo de liderança influencia positivamente a cultura organizacional e os resultados com os pacientes ${ }^{(7)}$ e é considerada nesse estudo um modelo adequado para o avanço na enfermagem.

Em um levantamento assistemático na literatura sobre o tema observamos como recomendação recorrente nas pesquisas a indicação da necessidade dos enfermeiros aprimorarem seus conhecimentos sobre liderança. Também são comuns apontamentos sobre a necessidade de se utilizar metodologias de maior impacto na prática.

Esses elementos motivaram o desenvolvimento dessa pesquisa, cujo enfoque foi a identificação, na literatura, de intervenções para o desenvolvimento de habilidades de liderança em enfermagem.

A imersão no tema mostrou que a pesquisa-ação foi um método citado em vários estudos, sinalizando que a intervenção viabilizou mudanças e construção de novos conhecimentos. As possibilidades de transformações durante o desenvolvimento de pesquisas dessa natureza vão surgindo à medida que participantes e pesquisadores vão se apropriando da situação a ser estudada ${ }^{(8)}$.

O início da utilização da pesquisa-ação como método de pesquisa não é muito precisa, mas atribui-se ao psicólogo social Kurt Lewin a responsabilidade pela criação e divulgação do processo de investigação, nos anos de 1940, com a formação dos T-groups (grupos de treinamento) cujo objetivo era provocar a reflexão nos indivíduos sobre suas próprias ações, como meio de desenvolver conhecimento e melhorar sua atuação ${ }^{(9-}$ 10)

Desde então, o método passou a ser cada vez mais explorado, trazendo para os participantes e pesquisadores a possibilidade de construir juntos, novas estratégias para implementação de mudanças. A pesquisa-ação pode ser compreendida como um tipo de pesquisa em que ocorre o processo simultâneo de investigação e ação, utilizada quando há interesse coletivo, tanto do pesquisador quanto dos participantes, na solução de problemas. O seu desenvolvimento prevê a resolução de situações cotidianas, requer mudanças de atitude na prática e tem caráter participativo e de capacitação dos participantes ${ }^{(8-12)}$. 
Considerando que a produção de conhecimento em uma pesquisa-ação prevê impacto na prática, no presente estudo buscou-se identificar a sua aplicabilidade para a transformação das práticas de liderança. Assim, delineou-se para esse estudo o objetivo de identificar as evidências sobre os efeitos do uso da pesquisa-ação no desenvolvimento da liderança em enfermagem.

\section{MÉTODOS}

Revisão integrativa de literatura cuja finalidade é reunir e sintetizar resultados de pesquisas de maneira sistemática e ordenada. Esse tipo de estudo tem o objetivo de aprofundar na temática, produzindo conhecimento capaz de direcionar a prática e o saber crítico ${ }^{(10)}$.

Essa revisão foi desenvolvida em etapas, sendo elas, a identificação do tema e seleção da questão de pesquisa; o estabelecimento de critérios para inclusão de estudos; a categorização; avaliação e interpretação dos resultados e finalmente, a apresentação da revisão/síntese do conhecimento ${ }^{(13-14)}$.

Para orientar o estudo foi utilizada como pergunta norteadora: quais os efeitos ou mudanças o uso da pesquisa-ação promovem no desenvolvimento da liderança em enfermagem?

A busca dos artigos foi realizada na PUBMED - Biblioteca Nacional de Medicina e na LILACS - Literatura Latino-Americana e do Caribe em Ciências da Saúde, tendo como critérios de inclusão: ser artigo original disponivel na íntegra on-line; em português, inglês, espanhol ou francês; referente aos últimos 10 anos; que apresentassem rigor metodológico na condução da pesquisa-ação no desenvolvimento de habilidades de liderança em enfermagem. Embora a ideia inicial fosse realizar a pesquisa nos últimos cinco anos, a escassez de material nos sugeriu ampliar a busca nos últimos 10 anos como forma de dar maior consistência a revisão.

Para o julgamento do rigor metodológico, considerou-se para a inclusão dos artigos aqueles que apresentavam as quatro fases do ciclo básico de investigação ${ }^{(10)}$. De acordo com o ciclo, as duas primeiras etapas compreendem a ação e correspondem ao movimento do diagnóstico/reconhecimento da realidade do campo de pesquisa e à ação propriamente dita. As demais dizem respeito ao processo investigativo, no qual há monitoramento e descrição dos efeitos da ação e avaliação de seus resultados ${ }^{(10)}$.

A busca foi realizada em outubro de 2016, orientada pelos descritores "Action Research" and "Nursing" adicionada à palavra-chave "pesquisa-ação" a fim de contemplar o maior número de artigos que abordassem a temática. Essa busca gerou um total de 1.889 artigos.

O detalhamento referente ao desenvolvimento da busca para obtenção dos resultados para a presente revisão está descritos na Figura 1. 


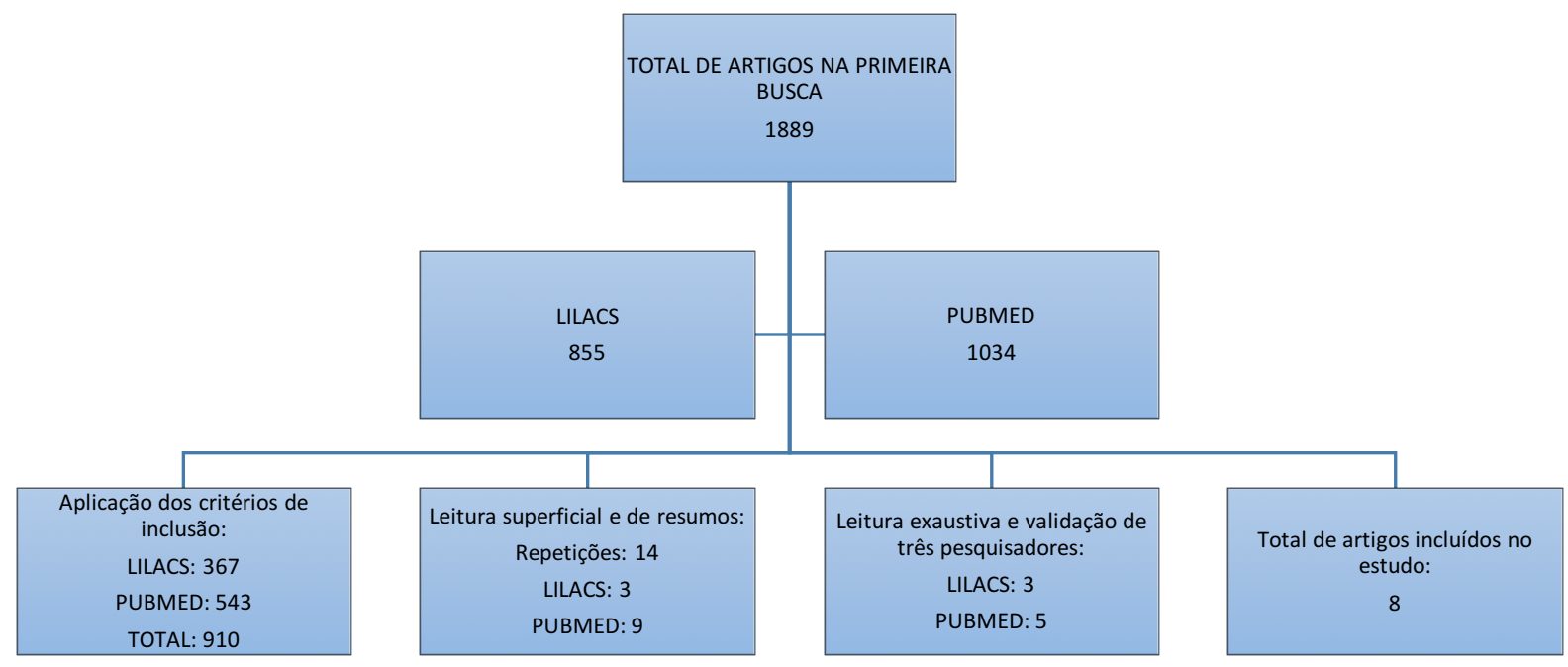

Figura 1: Detalhamento do desenvolvimento da busca para obtenção dos artigos.

O processo analítico foi feito concomitantemente por quatro pesquisadoras visando sua validação, sendo feito em duplas. A primeira etapa se deu por meio da aplicação dos critérios de inclusão do estudo, restando um total de 910 artigos. A seleção dos artigos com foco na temática do desenvolvimento da liderança foi feita pela leitura de todos os títulos e resumos e, posteriormente, da leitura dos artigos na íntegra daqueles que em primeira análise atendiam à temática.

Os artigos selecionados foram lidos exaustivamente e seus dados extraídos e organizados em um protocolo previamente elaborado com informações relevantes para atender a questão de pesquisa. Nesse processo o foco foi direcionado para: objetivo, rigor metodológico e referencial metodológico, resultados alcançados, buscando evidências dos efeitos do uso da pesquisa-ação no desenvolvimento de liderança em enfermagem, mudanças ocorridas e recomendações/limitações do estudo.

Após esse procedimento foram validados e incluídos no estudo oito artigos, cujos achados foram organizados em um quadro síntese para posterior análise descritiva, interpretação e apresentação da síntese do conteúdo da revisão.

\section{RESULTADOS}

O Quadro 1 sintetiza os dados encontrados nos artigos incluídos na revisão, ilustrando os efeitos do uso da pesquisa-ação no desenvolvimento de habilidades de liderança em enfermagem. 
Quadro 1: Evidências de efeitos e mudanças produzidas pelo uso da pesquisa-ação no desenvolvimento de habilidades de liderança em enfermagem.

\begin{tabular}{|c|c|c|c|}
\hline $\begin{array}{l}\text { Autores / Periódico / } \\
\text { Ano / Título / País }\end{array}$ & Objetivo / Contexto do Estudo & Resultados & $\begin{array}{l}\text { Evidências de Efeitos e Mudanças Produzidos pela } \\
\text { Pesquisa-Ação / Recomendações / Limitações }\end{array}$ \\
\hline $\begin{array}{l}\text { Šuc, Prokosch, Ganslandt } \\
\text { / Methods Inf Med / } \\
\text { (2009) / "Aplicabilidade } \\
\text { do modelo de gestão da } \\
\text { mudança de Lewin em } \\
\text { um ambiente hospitalar" } \\
\text { / Alemanha }\end{array}$ & $\begin{array}{l}\text { Objetivo: } \\
\text { - Ilustrar a aplicabilidade do método de } \\
\text { gerenciamento de mudanças de Kurt Lewin em um } \\
\text { projeto de inclusão de informática em saúde em um } \\
\text { hospital universitário } \\
\text { Contexto do Estudo: } \\
\text { - Pesquisa-ação realizada com base no referencial } \\
\text { metodológico no modelo de gestão da mudança de } \\
\text { Kurt Lewin. O artigo é parte de projeto mais } \\
\text { abrangente realizado em Hospital Universitário de } \\
\text { Erlangen/Alemanha sobre gerenciamento de material } \\
\text { cirúrgico por meio de processo de informatização na } \\
\text { instituição e superar barreiras sócio tecnológicas } \\
\text { identificadas entre pessoal de enfermagem. A } \\
\text { intervenção durou três meses e abrangeu } 15 \\
\text { especialidades cirúrgicas do hospital, envolvendo } \\
\text { toda equipe de Enfermagem do hospital. }\end{array}$ & $\begin{array}{l}\text { Resultados: } \\
\text { - No descongelamento foram realizadas oficinas de } \\
\text { discussão, possibilitando a compreensão coletiva dos } \\
\text { reais objetivos do projeto, garantindo-se que a } \\
\text { opinião e conhecimento da equipe de enfermagem } \\
\text { fosse considerada como altamente relevante na } \\
\text { implementação do processo de mudança de } \\
\text { gerenciamento do material cirúrgico. } \\
\text { - Na implementação da mudança, foi eleito um } \\
\text { responsável pela inclusão do novo conceito de } \\
\text { registro dos materiais em cada sala de cirurgia, que } \\
\text { se tornou a referencia local para a formação e apoio } \\
\text { na implementação do uso das tecnologias de } \\
\text { informática. } \\
\text { - Na fase de recongelamento, ajustes no processo } \\
\text { criaram códigos comuns para identificar o registro de } \\
\text { material ausente/incompleto no sistema de } \\
\text { informação; implementaram tarefas integradas no } \\
\text { fluxo de trabalho de registro regular e relatórios } \\
\text { individualizados sobre os dados de consumo de } \\
\text { material recém-documentados. }\end{array}$ & $\begin{array}{l}\text { Evidências de efeitos ou mudanças: } \\
\text { - Maior controle do processamento do material } \\
\text { cirúrgico; } \\
\text { - Adesão da equipe de enfermagem ao projeto } \\
\text { institucional, superando as barreiras iniciais e falta de } \\
\text { credibilidade no processo de mudança; } \\
\text { - Empoderamento das enfermeiras na liderança do } \\
\text { processo de mudança; } \\
\text { - Valorização da equipe de enfermagem nos } \\
\text { processos de tomada de decisão institucional; } \\
\text { - A responsabilidade pela futura manutenção dos } \\
\text { equipamentos foi transferida para a equipe de } \\
\text { enfermagem, a seu pedido. } \\
\text { Recomendações: } \\
\text { - Na aplicação desse modelo deve-se levar em conta } \\
\text { as características institucionais e o apoio para } \\
\text { implementação de mudanças; } \\
\text { - A aplicação do método utilizado deve ser } \\
\text { incentivada não só para projetos de implementação } \\
\text { de grandes sistemas de TI, mas também para } \\
\text { modificações de processos mais simples. } \\
\text { Limitações: } \\
\text { - O estudo foi limitado a apenas ao grupo } \\
\text { ocupacional da enfermagem. }\end{array}$ \\
\hline
\end{tabular}




\begin{tabular}{|c|c|c|c|}
\hline $\begin{array}{l}\text { Autores / Periódico / } \\
\text { Ano / Título / País }\end{array}$ & Objetivo / Contexto do Estudo & Resultados & $\begin{array}{l}\text { Evidências de Efeitos e Mudanças Produzidos pela } \\
\text { Pesquisa-Ação / Recomendações / Limitações }\end{array}$ \\
\hline $\begin{array}{l}\text { Macphee, Wardrop, } \\
\text { Campbell / Journal of } \\
\text { Nursing Management / } \\
\text { (2010) / "Transformando } \\
\text { as relações no local de } \\
\text { trabalho através da } \\
\text { tomada de decisão } \\
\text { compartilhada" / Canadá }\end{array}$ & $\begin{array}{l}\text { Objetivo: } \\
\text { - Explorar as ligações de estrutura-processo-resultado } \\
\text { (Donabedian) relacionadas com a liderança do } \\
\text { enfermeiro na tomada de decisão compartilhada. } \\
\text { Contexto do Estudo: } \\
\text { - Pesquisa-ação com base nos preceitos de Kurt } \\
\text { Lewin, organizado por meio de ciclos de } \\
\text { planejamento, atuação e reflexão, analisando as } \\
\text { relações de estrutura e processo entre os membros } \\
\text { da equipe do projeto, incluindo o líder da linha de } \\
\text { frente e entre a equipe do projeto e a liderança } \\
\text { organizacional, normalmente o líder de operações de } \\
\text { nível médio. O artigo ilustra parte de um projeto com } \\
\text { duração de três anos que incluiu intervenção por } \\
\text { meio de reuniões mensais, liberação de } 8 \text { hs semanais } \\
\text { para trabalhar no projeto; avaliação do impacto do } \\
\text { projeto na instituição. }\end{array}$ & $\begin{array}{l}\text { Resultados: } \\
\text { - O conflito foi entendido como um fator } \\
\text { determinante na tomada de decisão compartilhada, } \\
\text { já que em cada equipe havia um conflito associado } \\
\text { que bloqueava o processo todo. A gestão de } \\
\text { conflitos, então, foi acrescentada como sub processo } \\
\text { importante no projeto. } \\
\text { - A entrega dos projetos pelas equipes representou a } \\
\text { conclusão bem-sucedida do processo. As ações de } \\
\text { curto prazo foram valorizadas pelas equipes que se } \\
\text { sentiam valorizadas, atuantes e autônomas com a } \\
\text { concretização das ações } \\
\text { - Foi identificado o aumento no grau de } \\
\text { independência aliada a iniciativa de cada equipe bem } \\
\text { como seu poder de negociação para a concretização } \\
\text { do projeto. } \\
\text { - Fortalecimento dos vínculos de estrutura e processo } \\
\text { eficazes entre os membros da equipe e entre equipes } \\
\text { e seus líderes, chegando em resultados bem- } \\
\text { sucedidos. }\end{array}$ & $\begin{array}{l}\text { Evidências de efeitos ou mudanças: } \\
\text { - O manejo dos conflitos e a construção de relações } \\
\text { fortes com o outro propiciou a definição de uma } \\
\text { "nova identidade" e da redefinição de objetivos } \\
\text { comuns às equipes; } \\
\text { - Novos sentimentos foram experimentados pelas } \\
\text { equipes tais como o orgulho e o entusiasmo pelo } \\
\text { projeto comum. } \\
\text { - Os líderes transformaram as relações com as } \\
\text { equipes fornecendo independência e autonomia às } \\
\text { equipes. } \\
\text { Recomendações: } \\
\text { - Necessidade de suporte organizacional na } \\
\text { sustentabilidade da tomada de decisão } \\
\text { compartilhada. } \\
\text { - Para execução de intervenções desse porte deve-se } \\
\text { começar com uma análise do potencial real de } \\
\text { conflito entre membros da equipe, entre as equipes e } \\
\text { seus líderes de operações e organização. } \\
\text { Limitações: } \\
\text { - Necessidade de análises aprofundadas de cada caso } \\
\text { em particular, que de alguma forma influenciaram } \\
\text { nos resultados. }\end{array}$ \\
\hline
\end{tabular}




\begin{tabular}{|c|c|c|c|}
\hline $\begin{array}{l}\text { Autores / Periódico / } \\
\text { Ano / Título / País }\end{array}$ & Objetivo / Contexto do Estudo & Resultados & $\begin{array}{l}\text { Evidências de Efeitos e Mudanças Produzidos pela } \\
\text { Pesquisa-Ação / Recomendações / Limitações }\end{array}$ \\
\hline $\begin{array}{l}\text { Bucchi, Mira / Rev. Esc. } \\
\text { Enferm. USP / (2010) / } \\
\text { "Reelaboração do } \\
\text { treinamento admissional } \\
\text { de enfermeiros de } \\
\text { Unidade de Terapia } \\
\text { Intensiva" / Brasil }\end{array}$ & $\begin{array}{l}\text { Objetivo: } \\
\text { - Analisar e reestruturar o processo de treinamento } \\
\text { admissional (TA) o processo de treinamento } \\
\text { admissional do enfermeiro na Unidade de Terapia } \\
\text { intensiva (UTI), na perspectiva dos enfermeiros } \\
\text { hospitalares } \\
\text { Contexto do Estudo: } \\
\text { - Pesquisa-ação realizada com base no referencial de } \\
\text { Thiollent envolvendo as fases de diagnóstico, } \\
\text { intervenção, avaliação. O estudo foi realizado na UTI } \\
\text { de um hospital privado com enfermeiros com no } \\
\text { mínimo três anos de atuação. Onze enfermeiros } \\
\text { participaram do estudo que foi desenvolvido por } \\
\text { meio de grupo focal presencial e interlocução via e- } \\
\text { mail. Foram realizadas seis reuniões, de março a } \\
\text { maio de } 2008 \text {. }\end{array}$ & $\begin{array}{l}\text { Resultados: } \\
\text { - A pesquisa permitiu a reelaboração do processo de } \\
\text { TA de enfermeiro na UTI incluindo criação de novo } \\
\text { conceito, objetivos, definição de perfil desejado para } \\
\text { o ingressantes, metas a serem atingidas durante o } \\
\text { TA, tempo, estratégias e necessidades. Além disso foi } \\
\text { elaborado um fluxograma de } \\
\text { complexidade/competência das ações esperadas dos } \\
\text { enfermeiros. Os processos de avaliação foram } \\
\text { definidos para o TA e ainda o perfil do enfermeiro } \\
\text { instrutor. }\end{array}$ & $\begin{array}{l}\text { Evidências de efeitos ou mudanças: } \\
\text {-Readequação do TA; } \\
\text { - Autorreflexão por parte dos enfermeiros } \\
\text { integrantes da pesquisa com relação ao o que eles } \\
\text { esperam de um profissional e o profissional que eles } \\
\text { tem sido, principalmente no que diz respeito a } \\
\text { autonomia profissional do enfermeiro na UTI. } \\
\text { Recomendações: } \\
\text { - Avaliar criteriosamente os resultados do TA como } \\
\text { parte inicial de um processo educativo formador de } \\
\text { um profissional crítico-reflexivo, ético-político, não } \\
\text { devendo ser suplantado. } \\
\text { - O TA deve ser visto como um investimento pela } \\
\text { instituição por meio do qual se garante a } \\
\text { sobrevivência da instituição no mercado da saúde, } \\
\text { cada vez mais competitivo. } \\
\text { Limitações: } \\
\text { - Tempo despendido para a intervenção (10 horas) }\end{array}$ \\
\hline
\end{tabular}




\begin{tabular}{|c|c|c|c|}
\hline $\begin{array}{l}\text { Autores / Periódico / } \\
\text { Ano / Título / País }\end{array}$ & Objetivo / Contexto do Estudo & Resultados & $\begin{array}{l}\text { Evidências de Efeitos e Mudanças Produzidos pela } \\
\text { Pesquisa-Ação / Recomendações / Limitações }\end{array}$ \\
\hline $\begin{array}{l}\text { Motta, Munari, Nunes / } \\
\text { Rev. Eletr. Enf. / (2011) / } \\
\text { “Intervenção para } \\
\text { desenvolvimento de } \\
\text { enfermeiros gerentes em } \\
\text { um hospital público na } \\
\text { perspectiva da pesquisa- } \\
\text { ação" / Brasil }\end{array}$ & $\begin{array}{l}\text { Objetivo: } \\
\text { - Descrever o processo de desenvolvimento de } \\
\text { enfermeiros gerentes para melhor desempenho } \\
\text { profissional. } \\
\text { Contexto do Estudo: } \\
\text { - Pesquisa-ação fundamentada no referencial de Kurt } \\
\text { Lewin, realizada em um hospital público com } 24 \\
\text { enfermeiros gerentes vinculados a Diretoria de } \\
\text { Enfermagem, suas assessorias e aqueles que } \\
\text { desempenhavam atividades na coordenação das } \\
\text { diversas unidades do hospital, com no mínimo um } \\
\text { ano em função de coordenação, gerência ou } \\
\text { assessoria. Foram realizados } 20 \text { encontros quinzenais } \\
\text { de quatro horas, totalizando } 80 \text { horas de } \\
\text { intervenção. }\end{array}$ & $\begin{array}{l}\text { Resultados: } \\
\text { - Etapa exploratória e diagnóstica: o grupo fez ampla } \\
\text { reflexão sobre o papel da gerência para garantir a } \\
\text { sistematização dos processos nas unidades, } \\
\text { assegurando a qualidade e a humanização da saúde e } \\
\text { pactuou ações para o aperfeiçoamento do seu papel. } \\
\text { - Etapa Intermediária: diante das evidencias das } \\
\text { limitações da atuação e da necessidade de } \\
\text { aprofundar o aprendizado, o grupo mostrou-se muito } \\
\text { angustiado pelo grande desafio que teriam na } \\
\text { implementação de novas ações e não avançou na } \\
\text { dimensão prática do trabalho. No entanto, esse } \\
\text { processo levou a uma imersão do grupo para } \\
\text { aprender novas habilidades relacionadas ao } \\
\text { autoconhecimento, especialmente pelo espaço } \\
\text { sistemático oferecido ao grupo para seu encontro. } \\
\text { - Etapa Final: o grupo visualizou o papel singular } \\
\text { como enfermeiro gerente nos processos de ensinar, } \\
\text { acompanhar, apoiar e cobrar a execução eficiente } \\
\text { dos procedimentos e protocolos adotados pela } \\
\text { organização, além da importância de flexibilizar sua } \\
\text { postura para perceber as necessidades dos seus } \\
\text { colaboradores. }\end{array}$ & $\begin{array}{l}\text { Evidências de efeitos ou mudanças: } \\
\text { - Ao tomar consciência da sua realidade, o grupo } \\
\text { assume uma postura defensiva e pouco colaborativa } \\
\text { (Fuga e angústia). } \\
\text { - O grupo concluiu que o gerente precisa usar da sua } \\
\text { autoridade, sem autoritarismo, dosando bom senso e } \\
\text { assertividade. } \\
\text { - Os gerentes apreenderam que o seu papel envolve } \\
\text { a promoção de ambiente favorável para o } \\
\text { desenvolvimento do trabalho, oportunizando a } \\
\text { cooperação, a integração, a colaboração e a } \\
\text { participação de todos. } \\
\text { - O grupo de gerentes traçou um diagnóstico sobre si } \\
\text { mesmo, mapeando seus pontos fortes e seus pontos } \\
\text { a desenvolver. } \\
\text { Recomendações: Dar continuidade ao } \\
\text { acompanhamento do grupo investigado para seu } \\
\text { fortalecimento, especialmente para o aprendizado } \\
\text { sobre confiar, colaborar e trabalhar em grupo, bem } \\
\text { como a coesão do grupo que favorece a harmonia, a } \\
\text { integração e a interação, elementos indispensáveis } \\
\text { para a consolidação de mudanças. } \\
\text { Limitações: } \\
\text { - Durante a pesquisa, o grupo não conseguiu planejar } \\
\text { ações objetivas em direção a mudança da sua prática. }\end{array}$ \\
\hline
\end{tabular}




\begin{tabular}{|c|c|c|c|}
\hline $\begin{array}{l}\text { Autores / Periódico / } \\
\text { Ano / Título / País }\end{array}$ & Objetivo / Contexto do Estudo & Resultados & $\begin{array}{l}\text { Evidências de Efeitos e Mudanças Produzidos pela } \\
\text { Pesquisa-Ação / Recomendações / Limitações }\end{array}$ \\
\hline $\begin{array}{l}\text { Bish, Kenny, Nay / } \\
\text { Nursing and Health } \\
\text { Sciences / (2013) / } \\
\text { "Usando pesquisa-ação } \\
\text { participativa para } \\
\text { promover a liderança em } \\
\text { enfermeiros de hospitais } \\
\text { rurais australianos" / } \\
\text { Austrália }\end{array}$ & $\begin{array}{l}\text { Objetivo: } \\
\text { - Identificar problemas que podem ter impacto sobre } \\
\text { as estratégias para promover a liderança de } \\
\text { enfermeiros em hospitais rurais. } \\
\text { Contexto do Estudo: } \\
\text { - Pesquisa-ação realizada junto a cinco diretores de } \\
\text { enfermagem de hospitais rurais australianos. O grupo } \\
\text { foi mediado por um expert em pesquisa-ação e } \\
\text { vivenciou um cronograma de reuniões para tratar de } \\
\text { cinco temas identificados pelo grupo como } \\
\text { fundamentais para melhorar o seu desempenho na } \\
\text { liderança. }\end{array}$ & $\begin{array}{l}\text { Resultados: } \\
\text { - O grupo trabalhou em torno cinco temas-chave, } \\
\text { gerando indicadores para seu aprimoramento: } \\
\text { Disperse os mitos: } \\
\text { - A necessidade de mudança na compreensão a nível } \\
\text { comunitário sobre a prática das enfermeiras rurais e } \\
\text { a divulgação do papel da enfermeira na liderança e } \\
\text { na reforma em saúde. } \\
\text { Adote o pensamento do “big-picture": } \\
\text { - A necessidade dos líderes de buscar questões } \\
\text { globais e nacionais da enfermagem para a realidade } \\
\text { diária da enfermagem rural. } \\
\text { Conecte-se com os colegas: } \\
\text { - A necessidade de coesão entre as relações de } \\
\text { trabalho, tanto aquelas entre os enfermeiros } \\
\text { urbanos/ rurais, quanto com de outras áreas de } \\
\text { atuação. } \\
\text { Reflita sobre a sua própria conduta: } \\
\text { - A necessidade de autoconhecimento constante } \\
\text { como um elemento fundamental para o } \\
\text { desenvolvimento pessoal e profissional do líder. } \\
\text { Crie um "buy-in" organizacional: } \\
\text { - A necessidade de criar uma rede organizacional por } \\
\text { meio da co-gestão, apoio e colaboração formal e } \\
\text { informa; na consecução dos objetivos. }\end{array}$ & $\begin{array}{l}\text { Evidências de efeitos ou mudanças: } \\
\text { - Empoderamento do grupo de enfermeiras com } \\
\text { ampla compreensão dos aspectos do exercício da } \\
\text { liderança gerando maior conhecimento, confiança, } \\
\text { autoconhecimento, consciência e reflexão crítica. } \\
\text { Recomendações: Fortalecer a capacidade dos } \\
\text { enfermeiros como líderes e recomendar a } \\
\text { importância de se começar este processo de } \\
\text { preparação na graduação. } \\
\text { - Compreender a enfermagem como uma profissão } \\
\text { importante na reforma em saúde rural e os } \\
\text { benefícios da busca ativa pela melhora na liderança. } \\
\text { - Os resultados da pesquisa servem de impulso para a } \\
\text { continuidade do processo de desenvolvimento } \\
\text { iniciado a partir desse trabalho. } \\
\text { Limitações: } \\
\text { - Falta de tempo para que os participantes pudessem } \\
\text { compartilhar conhecimentos com colegas de trabalho } \\
\text { entre as reuniões. }\end{array}$ \\
\hline
\end{tabular}




\begin{tabular}{|c|c|c|c|}
\hline $\begin{array}{l}\text { Autores / Periódico / } \\
\text { Ano / Título / País }\end{array}$ & Objetivo / Contexto do Estudo & Resultados & $\begin{array}{l}\text { Evidências de Efeitos e Mudanças Produzidos pela } \\
\text { Pesquisa-Ação / Recomendações / Limitações }\end{array}$ \\
\hline $\begin{array}{c}\text { Mackoff, Glassman, } \\
\text { Budin / JONA / (2013) / } \\
\text { “Desenvolvimento de um } \\
\text { Laboratório de Liderança } \\
\text { para enfermeiros } \\
\text { Gestores Baseado em } \\
\text { experiências vividas" / } \\
\text { Estados Unidos da } \\
\text { América }\end{array}$ & $\begin{array}{l}\text { Objetivo: } \\
\text { - Desenhar um modelo inovador de desenvolvimento } \\
\text { de liderança, por meio de Laboratório de Liderança } \\
\text { (LL), baseada nas experiências vividas } \\
\text { Contexto do Estudo: } \\
\text { - Pesquisa-ação desenvolvida durante um ano, com } \\
43 \text { enfermeiros gestores como participantes, co- } \\
\text { criadores, avaliadores do projeto e os principais } \\
\text { beneficiários dos resultados do processo. } 0 \\
\text { Laboratório de Liderança fundamentado em quatro } \\
\text { pilares teóricos teve inicio com o levantamento de } \\
\text { necessidades de aprimoramento do grupo, } \\
\text { posteriormente foram realizadas sessões de três } \\
\text { horas para cada necessidade apontada pelo grupo, } \\
\text { repetida em } 4 \text { grupos distintos de } 10 \text { a } 15 \\
\text { enfermeiros. }\end{array}$ & $\begin{array}{l}\text { Resultados: } \\
\text { - Na Avaliação das necessidades de aprendizagem em } \\
\text { liderança dos enfermeiros gestores foram } \\
\text { selecionados três tópicos de maior relevância: } \\
\text { - } \quad \text { trabalho em equipe } \\
\text { - gestão do tempo à luz da missão } \\
\text { - gestão de conflitos } \\
\text { - Os três tópicos definiram o formato do Laboratório } \\
\text { de Liderança (LL) que foi realizado como um piloto, } \\
\text { os quais produziram resultados qualitativos e } \\
\text { quantitativos: } \\
\text { - Qualitativos - os enfermeiros identificaram a } \\
\text { importância do LL para oportunizar encontro com os } \\
\text { pares e receber apoio e validação das suas atuações. } \\
\text { - Quantitativos - mais de 35\% dos entrevistados } \\
\text { relataram o uso de estratégias de cada um dos LL } \\
\text { diariamente ou frequentemente. }\end{array}$ & $\begin{array}{l}\text { Evidências de efeitos ou mudanças: } \\
\text { - O encontro com pares forneceu maior } \\
\text { tranquilidade, conhecimento e confiança aos } \\
\text { enfermeiros gerentes na liderança. } \\
\text { - O projeto se mostrou assertivo ao retirar das } \\
\text { experiências dos próprios enfermeiros as } \\
\text { necessidades de aprendizagem. } \\
\text { Recomendações: } \\
\text { - O formato LL permite aperfeiçoamento e tem custo } \\
\text { inferior do que outros programas de } \\
\text { desenvolvimento para liderança, já que utilizam as } \\
\text { experiências prévias dos participantes para criar } \\
\text { estratégias de aprendizagem e resolução de } \\
\text { problemas. } \\
\text { - Educadores internos e ou gestores experientes } \\
\text { podem contribuir nos treinamentos, minimizando os } \\
\text { custos com facilitador externo. } \\
\text { Limitações: } \\
\text { - Dificuldade de generalização dos dados devida à } \\
\text { baixa adesão nas respostas aos inquéritos de } \\
\text { acompanhamento de } 1 \text { mês e } 1 \text { ano. }\end{array}$ \\
\hline
\end{tabular}




\begin{tabular}{|c|c|c|c|}
\hline $\begin{array}{l}\text { Autores / Periódico / } \\
\text { Ano / Título / País }\end{array}$ & Objetivo / Contexto do Estudo & Resultados & $\begin{array}{l}\text { Evidências de Efeitos e Mudanças Produzidos pela } \\
\text { Pesquisa-Ação / Recomendações / Limitações }\end{array}$ \\
\hline $\begin{array}{l}\text { Taylor, Roberts, Smyth, } \\
\text { Tulloch / Journal of } \\
\text { Nursing Management / } \\
\text { (2015) / “As estratégias } \\
\text { dos gerentes de } \\
\text { enfermagem para se } \\
\text { sentirem menos } \\
\text { esgotadas pelo seu } \\
\text { trabalho: um projeto de } \\
\text { pesquisa-ação e reflexão } \\
\text { para o desenvolvimento } \\
\text { da inteligência } \\
\text { emocional” / Austrália }\end{array}$ & $\begin{array}{l}\text { Objetivo: } \\
\text { - Aumentar a consciência crítica dos profissionais em } \\
\text { relação aos problemas práticos que gerentes de } \\
\text { enfermagem enfrentam; } \\
\text { - Trabalhar sistematicamente em conjunto } \\
\text { identificando restrições, para uma gestão eficaz de } \\
\text { enfermagem. } \\
\text { - Melhorar a eficácia do trabalho dos gerentes de } \\
\text { enfermagem à luz de suas limitações de trabalho } \\
\text { específico e possibilidades. } \\
\text { Contexto do Estudo: } \\
\text { - Pesquisa-ação realizada com três enfermeiros } \\
\text { gerentes de um hospital rural australiano que } \\
\text { trabalhavam juntas e coletivamente se dispuseram a } \\
\text { solucionar problemas aumentando a consciência } \\
\text { para mudança no seu papel gerencial. Os } \\
\text { enfermeiros se reuniam quinzenalmente em um } \\
\text { grupo, com duração de uma hora, no decorrer de dez } \\
\text { encontros. Os ciclos da pesquisa-ação. foram } \\
\text { subdivididos em duas fases principais: planejamento } \\
\text { (reuniões 1-8) e atuação, observação e reflexão } \\
\text { (reuniões 9-10). }\end{array}$ & $\begin{array}{l}\text { Resultados: } \\
\text { - Os resultados foram divididos em duas partes: } \\
\text { Parte um - Planejamento } \\
\text { - Os participantes identificaram seus sistemas de } \\
\text { valores, e o potencial de dissonância moral desses } \\
\text { com as questões do trabalho "agir fora"; } \\
\text { - Compartilharam situações problemáticas do } \\
\text { trabalho o que gerou um plano de ação com cinco } \\
\text { estratégias para ajuda-los a se sentir menos esgotado } \\
\text { pela intensidade do seu trabalho: } \\
\text { 1. Analisar situações problemáticas com } \\
\quad \text { colegas de confiança; } \\
\text { 2. Desviar várias solicitações de atenção e } \\
\quad \text { ação; } \\
\text { 3. Difundir questões com humor adequado } \\
\quad \text { durante e após situações problemáticas; } \\
\text { 4. Nomear comportamentos disfuncionais, } \\
\quad \text { preferencialmente no momento em que } \\
\quad \text { ocorrem; e } \\
\text { 5. Reagrupar tomando "tempo limite" } \\
\quad \text { durante e depois de situações } \\
\text { problemáticas. }\end{array}$ & $\begin{array}{l}\text { Evidências de efeitos ou mudanças: } \\
\text {-A intervenção permitiu que as participantes não } \\
\text { apenas compartilhassem suas experiências de } \\
\text { trabalho e fizeram ajustes positivos à sua prática, } \\
\text { mas também continuaram a desenvolver sua própria } \\
\text { inteligência emocional por meio da prática reflexiva. } \\
\text { Recomendações: } \\
\text { - A discussão da prática deve ocorrer em um lugar } \\
\text { privado e com tempo suficiente para permitir que a } \\
\text { complexidade das situações difíceis possam ser } \\
\text { descritas e dar tempo para quem expos o problema } \\
\text { recebe o feedback do grupo. } \\
\text { - É fundamental o contínuo desenvolvimento da } \\
\text { inteligência emocional para os enfermeiros gerentes. } \\
\text { Limitações: } \\
\text { - Apenas as estratégias adotadas na pesquisa não } \\
\text { foram suficientes para garantir que os gerentes não } \\
\text { se sentissem tão esgotados. }\end{array}$ \\
\hline
\end{tabular}




\begin{tabular}{|c|c|c|c|}
\hline $\begin{array}{l}\text { Autores / Periódico / } \\
\text { Ano / Título / País }\end{array}$ & Objetivo / Contexto do Estudo & Resultados & $\begin{array}{l}\text { Evidências de Efeitos e Mudanças Produzidos pela } \\
\text { Pesquisa-Ação / Recomendações / Limitações }\end{array}$ \\
\hline $\begin{array}{c}\text { Sade, Peres / Rev Esc } \\
\text { Enferm USP / (2015) / } \\
\text { "Desenvolvimento de } \\
\text { competências gerenciais } \\
\text { do enfermeiro: diretriz } \\
\text { para serviços de } \\
\text { educação permanente" / } \\
\text { Brasil }\end{array}$ & $\begin{array}{l}\text { Objetivo: } \\
\text { - Construir uma diretriz de educação permanente } \\
\text { para o desenvolvimento de competências gerenciais } \\
\text { para enfermeiros. } \\
\text { Contexto do Estudo: } \\
\text { - Pesquisa-ação fundamentada em Thiollent, } \\
\text { realizada junto a } 16 \text { enfermeiros participantes do } \\
\text { Núcleo de Enfermeiros de Educação Permanente do } \\
\text { Paraná- NEEP/PR/Brasil. Durante mais de um ano os } \\
\text { enfermeiros envolvidos trabalharam acompanhando } \\
\text { as etapas do processo de pesquisa-ação fazendo o } \\
\text { diagnóstico por meio de entrevistas; Seminário de } \\
\text { discussão e Seminários de Planejamento. }\end{array}$ & $\begin{array}{l}\text { Resultados: } \\
\text { - A pesquisa gerou aspectos relevantes para se } \\
\text { compreender as competências gerenciais que mais } \\
\text { demandam desenvolvimento, sendo a liderança e a } \\
\text { Educação Permanente, as mais citadas. } \\
\text { - Como dificuldades para o desenvolvimento de } \\
\text { competências gerenciais foram mencionadas a } \\
\text { dissociação entre ensino e serviço; a falta de } \\
\text { comprometimento dos profissionais enfermeiros; a } \\
\text { falta de recursos humanos, físicos e financeiros e a } \\
\text { falta de apoio do superior hierárquico. } \\
\text { - Além disso, propiciou a construção coletiva de uma } \\
\text { diretriz como estratégia para desenvolvimento de } \\
\text { competências do enfermeiro por meio de seus } \\
\text { Seminários, propondo uma modelagem. }\end{array}$ & $\begin{array}{l}\text { Evidências de efeitos ou mudanças: } \\
\text { - A construção coletiva da diretriz suscitou } \\
\text { sentimento de pertencimento ao grupo e de } \\
\text { valorização do NEEP/PR, como um espaço efetivo } \\
\text { para discussão e reflexão crítica na construção de } \\
\text { saberes. } \\
\text { - A pesquisa-ação promoveu a reflexão sobre a } \\
\text { realidade do processo de trabalho gerencial do } \\
\text { enfermeiro, ampliando a visão dos membros do } \\
\text { núcleo. } \\
\text { Recomendações: } \\
\text { - É possível desenvolver as competências gerenciais } \\
\text { do enfermeiro na lógica da Educação Permanente, } \\
\text { mas é preciso compreender essas competências para } \\
\text { além o indivíduo, mas contextualizada com as } \\
\text { situações reais da prática laboral. } \\
\text { Limitações: } \\
\text { - O tempo destinado à pesquisa não permitiu a } \\
\text { aplicação da diretriz necessária à produção de } \\
\text { conhecimentos teóricos e práticos relativos à } \\
\text { efetivação do programa de educação permanente. }\end{array}$ \\
\hline
\end{tabular}




\section{DISCUSSÃO}

As pesquisas foram desenvolvidas em diferentes países, com destaque para Brasil (três artigos) e Austrália (dois artigos), além de Canadá, Estados Unidos e Alemanha. Entre os anos de 2010 e 2015 foram produzidos seis, dos oito artigos, sendo que o estudo mais antigo foi publicado em 2009. As revistas Jornal of Nursing Management (dois artigos) e Revista da Escola de Enfermagem da USP (dois artigos) concentram a metade das publicações. O cenário de escolha para realização das pesquisas foi, principalmente, o ambiente hospitalar sendo dois em hospitais universitários, dois em hospitais rurais, além de centros médicos (dois) e um núcleo estadual de educação permanente (um).

Uma revisão sobre programas de desenvolvimento de liderança em enfermagem ${ }^{(15)}$, constatou que mais de $60 \%$ dos programas analisados estavam direcionados para a enfermagem em espaço hospitalar e nenhum foi concebido para os enfermeiros que trabalham em contextos da atenção primária ${ }^{(15)}$. Tais achados apontam certa semelhança com os resultados do nosso estudo. Embora especialistas em liderança em enfermagem, apontem para a importância estratégica de desenvolvimento de habilidades de liderança em enfermagem ${ }^{(16)}$, ações concretas nessa direção parecem restritas ao contexto hospitalar. Esse resultado reforça a necessidade de pesquisas que promovam impacto na prática no que diz respeito ao empoderamento do enfermeiro com maiores habilidades em liderança, já que esse profissional está inserido de forma expressiva em todos os níveis do cuidado em saúde e na gestão.

Os objetivos propostos nos artigos sinalizavam para diferentes formas de promover a liderança do enfermeiro. Assim, observa-se estudo que partiu de uma proposta mais ampliada de reestruturação organizacional incluindo a equipe de enfermagem como peça fundamental do processo de mudança e inclusão de novas ferramentas de trabalho ${ }^{(17)}$. A maioria dos estudos incluídos tiveram como objetivo viabilizar o desenvolvimento da liderança do enfermeiro partindo de suas dificuldades, desafios ou para aprimorar o seu desempenho ${ }^{(18-20)}$. Os demais artigos tiveram como caminho criar matrizes de desenvolvimento de liderança capazes de serem reproduzidas e de direcionarem processos de educação permanente ${ }^{(21-24)}$.

Quanto ao referencial metodológico utilizado na condução da pesquisa-ação, observa-se na maioria o uso de Kurt Lewin e Michel Thiollent. O desenho de todos os estudos se baseou em intervenções fundamentadas em processos colaborativos de solução de problemas da prática, envolvendo o ciclo reflexão, ação e avaliação, que ao longo do seu desenvolvimento promoveram mudanças pessoais e/ou institucionais. A duração dos estudos também foi variada, sendo que o mais longo levou três anos para ser realizado e o mais curto durou três meses.

Embora seja atribuída a Kurt Lewin ${ }^{(10)}$ a criação do processo da pesquisa-ação, ao longo dos anos outros pensadores foram aprimorando a ideia de construção da pesquisa a partir de problemas da prática, mais especificamente relacionadas a como melhorar o desempenho de grupos que tem uma tarefa comum. Apesar do ciclo de planejamento/reflexão-ação-avaliação ser uma constante nesse processo, ações podem ser diferentes em cada fase e delimitadas ao contexto do local onde se realiza a pesquisa, aos objetivos e 
metas que se pretende na promoção de mudanças em diferentes níveis, desde o local, até o mais complexo que envolve o grupo social como um todo ${ }^{(10)}$.

Em geral, os resultados dos artigos analisados mostram os desenhos das fases vivenciadas em um processo de pesquisa-ação, destacando no diagnóstico da situação/reflexão ou a fase de planejamento como o momento do acontecimento de discussões conjuntas, compreensão coletiva e identificação dos fatores determinantes, aspectos dificultadores, necessidades e valores relacionados ao exercício da liderança em enfermagem. Alguns desses levantamentos e fatores determinantes estão relacionados especialmente à gestão de conflitos ${ }^{(18,20,23)}$.

Na fase da ação os resultados dos estudos apontam a produção do grupo a partir das necessidades e aspectos levantados na fase anterior. Os estudos incluídos na pesquisa mostram que os enfermeiros se envolveram nas propostas apresentadas e criaram novas ferramentas de trabalho ${ }^{(17)}$, produziram projetos e planos de ação ${ }^{(18,20)}$, deram novos rumos para os treinamentos em serviço ${ }^{(21)}$ e tomaram consciência de aspectos que precisam ser melhorados e de novas necessidades ${ }^{(21-24)}$. Nessa fase a independência, 0 autoconhecimento, a iniciativa, o fortalecimento dos participantes enquanto grupo e o aumento do poder de negociação pelo empoderamento coletivo foram as atitudes identificadas como favoráveis ao melhor desempenho na liderança pelos enfermeiros ${ }^{(17-20,22-23)}$.

A análise da fase da avaliação ou reflexão da ação de cada artigo, observou-se que é possível a criação de inúmeras formas de "medir" o impacto das ações ou propostas de aperfeiçoamento do trabalho, sendo possível desde a criação de indicadores de implementação para novos processos de trabalho ${ }^{(17-19)}$, novos processos de avaliação conjunta ${ }^{(17,20,24)}$, fluxograma de complexidade/competência das ações esperadas para a liderança ${ }^{(21)}$ e a definição de perfil e papéis a serem desenvolvidos no exercício da liderança em enfermagem ${ }^{(19,22,24)}$. Vale destacar que, pela natureza interativa e participativa do método, é comum o maior impacto dos resultados e efeitos relacionados à dimensão subjetiva do trabalho coletivo. No quadro síntese, na coluna dedicada aos efeitos/mudanças evidenciadas, todos os artigos trazem de algum modo um aspecto relacionado a essa dimensão do trabalho.

Tais efeitos e mudanças descritas nos artigos incluídos na pesquisa apontam impactos tanto em relação ao próprio enfermeiro na liderança ${ }^{(17-24)}$ quanto às mudanças relacionadas às equipes de trabalho ${ }^{(17,20,22)}$. Estudos mostraram que os enfermeiros vivenciaram um processo de autorreflexão e autocrítica que gerou empoderamento e identificação no papel de liderança ${ }^{(18-19,21,23-24)}$. A partir do momento em que os enfermeiros tomaram consciência de si (autoconhecimento) e de suas ações, foi possível projetar o que precisavam ser, trazendo conhecimento, confiança e criação de uma "nova identidade"(19-20,24).

Em relação às equipes, os artigos apontam para mudanças e efeitos no sentimento de pertencimento dos profissionais às equipes ${ }^{(22)}$. Entre as evidências estão a redefinição de objetivos comuns ${ }^{(17,20)}, 0$ surgimento de novos sentimentos: orgulho e entusiasmo por fazer parte ${ }^{(20)}$, a tomada de responsabilidade dos profissionais pelos projetos institucionais ${ }^{(17)}$ e a sensação de autonomia e independência ${ }^{(20)}$.

No contexto organizacional, destaca-se entre os artigos estudados um publicado na Alemanha que 
trata de um projeto de mudança organizacional planejada (MOP), do qual a equipe de enfermagem foi fundamental para implementação de um novo processo de trabalho, sendo protagonista, a partir de então, de uma mudança organizacional mais complexa ${ }^{(17)}$. Esse artigo mostra o potencial de alcance da pesquisaação para além dos resultados subjetivos, embora esses fossem também a base da mudança mais complexa e que refletiu em toda a organização.

A MOP é uma modalidade de pesquisa-ação proposta por Kurt Lewin na metade do século $X X^{(9,25-26)}$ adequada para se desenvolver no contexto organizacional, na qual a mudança se organiza em três fases: descongelamento, movimento e recongelamento. No descongelamento é preciso haver um desequilíbrio ou crise interna que propicie alteração de percepção e introdução de novas ideias, sentimentos, atitudes e comportamentos. Nessa fase, as pessoas precisam ser motivadas a sair do status quo nas quais se encontram, acreditando que haja uma necessidade de mudança e interesse por ela. A mudança só ocorrerá por razões significativas. Nesse sentido, o descongelamento acontece pelos questionamentos, novas informações que provocam surpresas, dúvidas, insatisfação, levando à sensibilização e conscientização de problemas e da necessidade de algumas mudanças ${ }^{(25-26)}$. O recongelamento é comparado a fase de avaliação onde se pode vislumbrar o impacto das mudanças que podem ser mensurados por mudanças comportamentais mas, sobretudo, por indicadores objetivos de mudanças processuais propostas na pesquisa. No caso do artigo em questão ${ }^{(17)}$, as mudanças vieram não só na implementação de um controle informatizado de material cirúrgico em todo o hospital, mas também de uma mudança de postura da equipe de enfermagem que passou a fazer o gerenciamento desse processo a seu pedido.

O desenho e a condução das pesquisas incluídas nesta revisão foram criteriosamente descritos, facilitando a constatação de que a aplicação rigorosa do método pode levar a um resultado mais objetivo e factível apontando efeitos e mudanças na prática. Tal resultado é possível pela aplicação criteriosa dos critérios de inclusão dos artigos, sendo o rigor metodológico na condução da pesquisa, o mais importante ${ }^{(10)}$. Por essa razão os participantes dos estudos foram levados a refletir sobre suas práticas, identificar problemas e vislumbrar as mudanças possíveis, em especial, partindo do reconhecimento dos fatores que dificultam essa mudança e do autoconhecimento como chave motora desse processo.

No que tange ao conceito de liderança utilizado como base no desenvolvimento dos estudos, observou-se que os fundamentos da liderança transformacional ${ }^{(27-28)}$ foi a base de todos os artigos. Esse referencial pressupõe que meios/ferramentas para desenvolver a liderança devem se alicerçar em uma relação de colaboração entre os membros das equipes e entre as equipes e seus líderes, cujo objetivo leva ao desencadeamento de mudanças no contexto em questão, promovendo o trabalho em equipe e a tomada de decisão compartilhada em prol do beneficio organizacional.

$\mathrm{Na}$ base conceitual da liderança transformacional considera-se a situação envolvida, a cultura da organização, os valores do líder e de seus colaboradores, o trabalho, o ambiente, a influência do líder e a complexidade das situações ${ }^{(7,27)}$. Esse caráter dinâmico, processual e sistêmico da liderança transformacional parece ter uma conexão interessante com o que infere os pressupostos da pesquisa-ação, pois considera que 
para projetar determinadas mudanças na perspectiva no processo de liderar é fundamental que os participantes do processo possam contribuir, "compartilhando o sonho" e conduzir a organização em direção ao futuro, em um movimento conjunto ${ }^{(7,26-27)}$.

Para desenvolver liderança nessa perspectiva é necessário que haja além do aprimoramento da pessoa do líder, com a ampliação de seu autoconhecimento, foco no desenvolvimento de todos os colaboradores e na transformação na cultura organizacional, para que haja mudança de conduta de todos os envolvidos ${ }^{(27)}$.

As recomendações decorrentes dos estudos para aprimoramento da prática indicam que sejam levadas em consideração as características institucionais; que as organizações apoiem e valorizem o processo de desenvolvimento de liderança em enfermagem. Também é recomendado um estudo prévio sobre os conflitos e sobre a situação vivenciada pelos participantes, a fim de contextualizar o objetivo e garantir de que o mesmo faça sentido aos participantes da pesquisa. Nesse tipo de pesquisa também foi sinalizado a necessidade de monitoramento dos resultados, podendo esse gerar outros processos de aperfeiçoamento do trabalho coletivo.

A pesquisa-ação, por sua natureza de envolver os participantes em um processo que propicia uma postura ativa, mostrou-se favorável ao desenvolvimento de habilidades de liderança entre enfermeiros, bem como de favorecer processos de mudanças. Por outro lado, as evidências apontam que para maior êxito, o envolvimento/apoio institucional é imprescindível para que possíveis mudanças ou implementação de novos processos recebam suporte da organização.

E, por fim, a maioria dos estudos cita a incapacidade de se generalizar estudos dessa natureza, o que de certa forma é compreensível, já que se trata de pessoas e contextos específicos de investigação/ação.

\section{CONCLUSÃO}

A intenção ao se desenvolver o presente estudo foi buscar evidências sobre os efeitos/mudanças produzidas em estudos sobre o desenvolvimento da liderança em enfermagem que utilizaram como método a pesquisa-ação. Compreender o alcance dessa metodologia na produção de mudanças na prática e identificar os seus resultados é fundamental para aprimorar o seu uso, controlar com mais rigor o processo investigativo de modo a ampliar as chances de que, de fato, o estudo tenha impacto.

Em particular, na temática de liderança em enfermagem é fundamental que sejam aprimoradas não apenas as práticas, mas os processos investigativos e desenvolvimento de modelos mais eficientes de liderança, de modo a gerar evidências mais robustas.

O impacto da pesquisa para a prática foi a constatação, de todos os estudos de que o método é capaz de produzir modificações nas práticas gerenciais dos enfermeiros, mesmo que apenas na dimensão reflexiva. Três, dos oito estudos apresentam resultados que mudaram a dinâmica do serviço, além de mudanças comportamentais na prática gerencial. Os cinco estudos restantes, trazem essa dimensão como a mais importante ou significativa no desenvolvimento da pesquisa. Assim, é possível afirmar que as evidências apresentadas pelos estudos parecem não se encerrarem com o fim da pesquisa, pois como pressuposto da 
própria metodologia, os processos iniciados com uma investigação-ação são cíclicos e a reflexão iniciada com a intervenção, continua na aplicação prática dos conhecimentos gerados.

Vale destacar como efeitos/mudanças mais relevantes nos estudos o empoderamento dos participantes com conhecimentos que ampliaram, sobretudo, o autoconhecimento como ferramenta de melhorar o desempenho do gerente, mostrando que se trata de metodologia capaz de trabalhar essa dimensão com eficiência. Resultados como melhoria da autonomia, satisfação no trabalho, empoderamento e reflexão crítica coletiva, denotam impacto e transformação nos espaços em que os estudos foram desenvolvidos, reforçando a importância estratégica do desenvolvimento de habilidades de liderança dos enfermeiros, não só como demanda para a pesquisa, mas para promoção de impacto na prática.

Em pesquisas dessa natureza, em que é considerada a subjetividade dos sujeitos envolvidos, é preciso que surja o reconhecimento da necessidade real de mudança pelos envolvidos para só assim levar à mudança. Nos estudos apresentados, fica clara a vontade de modificar a prática e os contextos vividos por parte dos sujeitos, que se comprometem a vivenciar a intervenção e avançam no sentido de produzir ferramentas que os apoiem.

As limitações mais comumente apontadas pelos autores foram relacionadas ao pouco tempo para a realização de alguns estudos, comprometendo uma reflexão mais aprofundada para os participantes. Também o fato de se realizar os estudos em setores específicos e não na organização como um todo, parecem diminuir o impacto nas relações de líderes e liderados existentes, porque não se tornam parte da cultura organizacional como um todo.

Como lacunas identificadas nessa revisão está a ausência de resultados que tenham impacto na formação das novas gerações de líderes. A formação para a sucessão de lideranças deve ser considerada estratégica pela enfermagem, tanto como constituinte do ciclo de qualificação e desenvolvimento da liderança na área, quanto para se manter e ampliar os espaços conquistados pela profissão. Também fica evidente a necessidade da enfermagem se apropriar de modelos de liderança mais eficientes e adequados ao mundo atual, como a liderança transformacional por exemplo, pelo impacto que essa tem, sobretudo, na mobilização e desenvolvimento de novas lideranças.

\section{REFERÊNCIAS}

1. Moore LW, Sublett C, Leahy C. Nurse managers' insights regarding their role highlight the need for practice changes. Appl Nurs Res [Internet]. 2016 [acesso em: 28 nov. 2017];30:98-103. Disponível em: http://doi.org/10.1016/j.apnr.2015.11.006.

2. Posner B, Kouzes J. O desafio da liderança: como aperfeiçoar sua capacidade de liderar. Rio de Janeiro: Elsevier; 2013.

3. Scully NJ. Leadership in nursing: The importance of recognising inherent values and attributes to secure a positive future for the profession. Collegian [Internet]. 2015 [acesso em: 28 nov. 2017];22(4):439-44. Disponível em: http://doi.org/10.1016/j.colegn.2014.09.004. 
4. Santos JLG, Pestana AL, Guerrero P, Meirelles BSH, Erdmann AL. Práticas de enfermeiros na gerência do cuidado em enfermagem e saúde: revisão integrativa. Rev Bras Enferm [Internet]. 2013 [acesso em: 28 nov. 2017];66(2):257-63. Disponível em: http://doi.org/10.1590/S0034-71672013000200016.

5. Munari DB, Chaves LDP, Peduzzi M, Laus AM, Fugulin FMT, Ribeiro LCM, et al. Cenário das pesquisas na pósgraduação na área de enfermagem e gerenciamento no Brasil. Rev Esc Enferm USP [Internet]. 2011 [acesso em: 28 nov. 2017];45(esp.):1543-50. Disponível em: http://doi.org/10.1590/S0080-62342011000700002.

6. Silva DS, Bernardes A, Gabriel CS, Rocha FLR, Caldana G. A liderança do enfermeiro no contexto dos serviços de urgência e emergência. Rev. Eletr. Enf. [Internet]. 2014 [acesso em: 28 nov. 2017];16(1):211-9. Disponível em: https://doi.org/10.5216/ree.v16i1.19615.

7. Fischer SA. Transformational leadership in nursing: a concept analysis. J Adv Nurs [Internet]. 2016 [acesso em: 28 nov. 2017];72(11):2644-53. Disponível em: http://doi.org/10.1111/jan.13049.

8. Williamson G, Bellman L, Webster J. Action research in nursing and healthcare. Califórnia: SAGE; 2012.

9. Lewin K. Action Research and Minority Problems. Journalof Social Issues [Internet]. 1946 [acesso em: 28 nov. 2017];2(4):34-46. Disponível em: http://doi.org/10.1111/j.1540-4560.1946.tb02295.x.

10. Tripp D. Pesquisa-ação: uma introdução metodológica. Educ e Pesqui [Internet]. 2005 [acesso em: 28 nov. 2017];31(3):443-66. Disponível em: http://dx.doi.org/10.1590/S1517-97022005000300009.

11. Grittem L, Meier MJ, Zagonel IPS. Pesquisa-ação: uma alternativa metodológica para pesquisa em enfermagem. Texto Context - Enferm [Internet]. 2008 [acesso em: 28 nov. 2017];17(4):765-70. Disponível em:

http://doi.org/10.1590/S0104-07072008000400019.

12. Monteiro CFS, Moreira MRC, Oliveira EAR, Moura MES, Costa JV. Pesquisa-ação: contribuição para prática investigativa do enfermeiro. Rev Gaucha Enferm [Internet]. 2010 [acesso em: 28 nov. 2017];31(1):167-74. Disponível em: http://doi.org/10.1590/S1983-14472010000100023.

13. Ganong LH. Integrative reviews of nursing research. Res Nurs Health [Internet]. 1987 [acesso em: 28 nov. 2017];10(1):1-11. Disponível em: http://doi.org/10.1002/nur.4770100103.

14. Whittemore R, Knafl K. The integrative review: updated methodology. J Adv Nurs [Internet]. 2005 [acesso em: 28 nov. 2017];52(5):546-53. Disponível em: http://doi.org/10.1111/j.1365-2648.2005.03621.x.

15. O'Neil E, Morjikian RL, Cherner D, Hirschkorn C, West T. Developing nursing leaders: an overview of trends and programs. J Nurs Adm [Internet]. 2008 [acesso em: 28 nov. 2017];38(4):178-83. Disponível em:

http://doi.org/10.1097/01.NNA.0000312754.61170.fa.

16. Cummings GG, MacGregor T, Davey M, Lee H, Wong CA, Lo E, et al. Leadership styles and outcome patterns for the nursing workforce and work environment: a systematic review. Int J Nurs Stud [Internet]. 2010 [acesso em: 28 nov.

2017];47(3):363-85. Disponível em: http://doi.org/10.1016/j.ijnurstu.2009.08.006.

17. Suc J, Prokosch HU, Ganslandt T. Applicability of Lewin's Change Management Model in a Hospital Setting.

Methods Inf Med [Internet]. 2009 [acesso em: 28 nov. 2017];48(5):419-28. Disponível em:

http://doi.org/10.3414/ME9235.

18. Taylor B, Roberts S, Smyth T, Tulloch M. Nurse managers' strategies for feeling less drained by their work: an action research and reflection project for developing emotional intelligence. J Nurs Manag [Internet]. 2015 [acesso em: 28 nov. 2017];23(7):879-87. Disponível em: http://doi.org/10.1111/jonm.12229.

19. Bish M, Kenny A, Nay R. Using participatory action research to foster nurse leadership in Australian rural hospitals. Nurs Health Sci [Internet]. 2013 [acesso em: 28 nov. 2017];15(3):286-91. Disponível em:

http://doi.org/10.1111/nhs.12030.

20. MacPhee M, Wardrop A, Campbell C. Transforming work place relationships through shared decision making. J Nurs Manag [Internet]. 2010 [acesso em: 28 nov. 2017];18(8):1016-26. Disponível em: http://doi.org/10.1111/j.13652834.2010.01122.x.

21. Bucchi SM, Mira VL. Reelaboração do treinamento admissional de enfermeiros de Unidade de Terapia Intensiva. Rev Esc Enferm USP [Internet]. 2010 [acesso em: 28 nov. 2017];44(4):1003-10. Disponível em:

http://doi.org/10.1590/S0080-62342010000400021.

22. Sade PMC, Peres AM. Development of nursing management competencies: guidelines for continuous education services. Rev Esc Enferm USP [Internet]. 2015 [acesso em: 28 nov. 2017];49(6):988-94. Disponível em:

http://doi.org/10.1590/S0080-623420150000600016. 
23. Mackoff BL, Glassman K, Budin W. Developing a leadership laboratory for nurse managers based on lived experiences: a participatory action research model for leadership development. J Nurs Adm [Internet]. 2013 [acesso em: 28 nov. 2017];43(9):447-54. Disponível em: http://doi.org/10.1097/NNA.0b013e3182a23bc1.

24. Motta KAMB, Munari DB, Nunes FC. Intervenção para desenvolvimento de enfermeiros gerentes em um hospital público na perspectiva da pesquisa ação. Rev. Eletr. Enf. [Internet]. 2011 [acesso em: 28 nov. 2017];13(4):629-38. Disponível em: https://doi.org/10.5216/ree.v13i4.9149.

25. Medley BC, Akan OH. Creating positive change in community organizations: A case for rediscovering Lewin. Nonprofit Manag Leadersh [Internet]. 2008 [acesso em: 28 nov. 2017];18(4):485-96. Disponível em:

http://doi.wiley.com/10.1002/nml.199.

26. Shirey MR. Lewin's Theory of Planned Change as a strategic resource. J Nurs Adm [Internet]. 2013 [acesso em: 28 nov. 2017];43(2):69-72. Disponível em: http://doi.org/10.1097/NNA.0b013e31827f20a9.

27. Posner B, Kouzes J. O desafio da liderança: como aperfeiçoar sua capacidade de liderar. Rio de Janeiro: Elsevier; 2013.

28. Doody O, Doody CM. Transformational leadership in nursing practice. Br J Nurs [Internet]. 2012 [acesso em: 28 nov. 2017];21(20):1212-8. Disponível em: https://doi.org/10.12968/bjon.2012.21.20.1212. 